\title{
PENERAPAN MODEL TERAPI LINGUISTIK UNTUK MENINGKATKAN KEMAMPUAN BERBICARA PENDERITA DISARTRIA
}

\author{
Gusdi Sastra dan Noviatri \\ Fakultas Ilmu Budaya Universitas Andalas
}

\begin{abstract}
Abstrak
Penelitian tentang terapi linguistik sudah banyak dilakukan terhadap pasien yang menderita disartria. Disartria adalah gangguan dalam bertutur yang disebabkan oleh kerusakan sistem saraf pusat yang secara langsung mengontrol aktivitas otot-otot yang berperan dalam proses tuturan dalam pembentukan suara pengucapan. Kajian ini membahas tiga isu, yakni bentuk-bentuk lingual dapat diterapkan pada penderita disartria sebelum memperoleh terapi linguistik, pengaruh-pengaruh emosional terhadap pengetahuan leksikal dan semantis dari pasien, dan capaian model terapi linguistik yang diterapkan pada pasien disartria yang kemampuan bertuturnya sudah cacat. Dalam menganalisis data, kajian ini menggunakan teori Prins (2004) dan metode Nunan (1992) yang dipadu dengan Sudaryanto (1993). Bersadarkan penelitian yang sudah dilakukan sebelumnya, dan dengan menerapkan model terapi linguistik, ditemukan bahwa terdapat peningkatan berbicara pasien, hampir 40 persen dari indeks pengetahuan atau informasi lingual, 20 persen semantik, dan 40 persen perasaan. Indeks lingual sangat penting sebagai sebuah cara terapi bagi pasien yang menderita disartria. Peningkatan dalam kemampuan bertutur ini menambah rasa percaya diri bagi penderita disatria di dalam kehidupan sosial.
\end{abstract}

Kata kunci: disartria, terapi linguistik, indeks lingual

\begin{abstract}
Research on linguistic therapy has been conducted on patients with dysarthria, dysarthria is a disorder of articulation due to impairment of the central nervous system, which directly controls the activity of the muscles that play a role in the process of articulation in the formed of pronunciation. This study discusses three issues, lingual forms can be done by people with dysarthria before getting linguistic theraphy, emotional infuences on lexical and semantic knowledge of the patient, and the achievement of the linguistic model of therapy applied to patients with dysarthria speech impairment. The theory used in this study was Prins (2004) and the method used is the method Nunan (1992) combined with Sudaryanto (1993) in analyzing the data. Based on the research that has been done, and by applying linguistic models of therapy, it was found that there is an patient increased ability to talk, nearly 40 percent of the index lingual knowledge or information, 20 percent of semantics, and 40 percent feeling. Lingual index is significant as a means of therapy for patients with dysarthria linguistics. An increase in this speech, adding confidence and self-patients dysarthria in addressing social life.
\end{abstract}

Keywords: dysarthria, linguistic theraphy, lingual index

Ranah, Volume 2, Nomor 2, Desember 2013 | 1 


\section{Pendahuluan}

Dalam penggunaaan bahasa verbal, setiap manusia dibekali kemampuan untuk berbahasa. Akan tetapi, kemampuan tersebut pada manusia berbeda, ada yang normal dan ada yang tidak normal. Orang yang tidak mampu berbahasa secara normal, banyak ditemui di tengah-tengah masyarakat, salah satunya adalah apa yang diderita oleh seorang penderita disartria akibat dari gangguan bicara yang dialaminya. Kerusakannya mungkin di bagian saraf bahasa pada otak akibat sesuatu, pada alat artikulasi, atau akibat tekanan mental sehingga ia kehilangan kemampuan dalam berbahasa atau mengalami gangguan saraf motorik kortikal berbahasa.

Penelitian terhadap gangguan motorik kortikal berbahasa, khususnya terhadap penderita berbahasa dan berbicara telah dilakukan. Tidak saja oleh dokter ahli saraf (neurolog), tetapi beberapa tahun terakhir, terutama sejak munculnya penelitian neurolinguistik di Indonesia oleh Suhardiyanto (2000) sebagai ahli bahasa (linguis), maka telah dimulai penelitian dari aspek kebahasaan terhadap penderita gangguan berbahasa. la mengkaji gejala segmental berbahasa yang dialami oleh seorang penderita afasia broca. Penelitian tersebut membuktikan bahwa ahli bahasa dapat memberikan sumbangan terhadap ilmu neurolog terutama dalam hal melihat aspek linguistik penderita gangguan berbahasa. Kemudian Sastra (2005), melakukan penelitian gangguan berbahasa pada penderita afasia penutur bahasa Minangkabau. Pada tahun 2007, Sastra juga telah mencoba mengembangkan penelitian gangguan berbahasa pada penderita afasia kepada aspek terapi bahasanya, yang dapat digunakan untuk meningkatkan kemampuan berbahasa dan berbicara.

Salah satu dari sekian banyak gangguan berbicara yang diakibatkan adanya gangguan berbahasa adalah disartria. Travis (1971) mendefinisikan disartria sebagai gangguan dalam bertutur yang disebabkan oleh kerusakan sistem saraf pusat yang secara langsung mengontrol aktivitas otot-otot yang berperan dalam proses tuturan dalam pembentukan suara pengucapan. Hilangnya kontrol otot-otot ini mungkin dapat berupa kelemahan, perlambatan atau nonkoordinasi. Gangguan berbicara ini menunjukkan gangguan di dalam pelaksanaan pola-pola motorik wicara yang mengarah kepada kelumpuhan, kelemahan, atau kesalahan dalam mengorganisasikan otot-otot wicara.

Penderita disartria tidak mengalami kesulitan dalam memahami suatu ujaran, membaca, dan menulis. Mereka hanya mengalami kesulitan dalam mengujarkan suatu ujaran. Selain itu, ketidakmampuan dalam berbicara pada penderita disartria dapat disebabkan oleh kelainan atau gangguan bawaan pada bagian lidah yang sulit digerakkan. Gangguan pada gerakan lidah ini mengakibatkan kesulitan dalam berbahasa lisan. Disartria ini terjadi karena adanya gangguan koordinasi antara otot pernapasan, laring, pharing, langit-langit, lidah, dan bibir. (Evans, 1999). Disartria merupakan gangguan bahasa yang lebih kepada bagaimana perintah dan koordinasi berbagai jenis motorik untuk menghasilkan suatu tuturan menjadi terganggu yang disebabkan oleh terganggunya artikulasi di rongga mulut. Gejala disartria ini sering terjadi ketika seseorang sedang berinteraksi secara lisan. (Sastra, 2010)

Dengan dimikian, penelitian terhadap gangguan verbal yang diderita oleh penderita disartria, perlu dilakukan. Penerapan Model Terapi Lingusitik (selanjutnya disingkat MTL) dirancang untuk terapi bahasa dengan metode terapi perilaku (Sastra, 2007) sehingga dapat mengungkapkan bagaimana penderita disartria berpikir dan mengekspresikan perasaannya 
untuk upaya kesembuhan. Model terapi ini dapat membantu penderita dalam upaya kesembuhan kemampuan berbicaranya agar dapat berkomunikasi dengan orang lain.

Berdasarkan pemikiran tersebut, penelitian ini merumuskan permasalahan dengan mengemukakan pertanyaan (1) bagaimanakah bentuk lingual yang dapat dilakukan oleh penderita disartria?, (2) seberapa jauhkah emosi berpengaruh terhadap pengetahuan leksikal dan semantik penderita disartria?, dan (3) bagaimanakah pencapaian MTL terhadap gangguan berbicara penderita disartria? Semua permasalahan tersebut dirumuskan dalam kerangka upaya untuk meningkatkan kemampuan berbahasa para penderita disartria sehingga mereka mampu berkomunikasi sebagaimana manusia normal melalui MTL.

Selain itu, berdasarkan permasalahan yang sudah dirumuskan, penelitian ini bertujuan untuk (1) mengungkapkan bentuk-bentuk lingual yang dapat dilakukan oleh penderita disartria, (2) menjelaskan bukti-bukti bahwa emosi berpengaruh terhadap pengetahuan leksikal dan semantik penderita disartria, dan (3) menemukan indeks pencapaian MTL yang diterapkan terhadap gangguan berbahasa para penderita disartria.

Dengan adanya penelitian ini, diharapkan adanya kerja sama antara ahli bahasa dengan ahli saraf dalam menangani permasalahan yang diderita oleh penderita gangguan berbicara khususnya disartria. Di samping itu, penelitian ini akan bermanfaat, antara lain sebagai berikut.

a. Bagi para penderita disartria, upaya penyembuhan melalui metode ini sangat diperlukan sehingga mereka merasakan bahwa penyakit disartria yang dideritanya akan dapat disembuhkan, meskipun terdapat gejala kelumpuhan dalam berkomunikasi dengan orang lain.

b. Bagi keluarga penderita disartria, perhatian yang dilakukan terhadap penderita akan dapat dipedomani melalui contoh terapi linguistik dengan MTL ini.

c. Bagi pihak rumah sakit terutama bagian saraf, penerapan MTL ini merupakan sesuatu yang baru dan perlu dikembangkan sehingga terapi bahasa yang selama ini tidak menggunakan pendekatan linguistik dengan MTL, akan dapat ditingkatkan.

d. Tidak itu saja, kegiatan ini memberikan kesadaran kepada masyarakat apabila di kelompok sosialnya terdapat penderita disartria diharapkan dapat memberikan keyakinan bahwa sakit yang dihidapnya dapat disembuhkan melalui MTL. Metode ini tidak saja untuk penyembuhan fisikal tetapi juga emosional yang diderita oleh penderita.

e. Bagi pihak pemerintahan, terutama dinas kesehatan kota Padang, dengan adanya kegiatan ini dapat memantau jumlah penderita disartria yang ada di kota Padang. Selain itu, upaya apa yang telah dilakukan dalam menangani kesembuhan penderita, terutama dari kemampuan berbahasa yang dimilikinya untuk berkomunikasi, baik komunikasi lisan maupun komunikasi tertulis.

f. Akhirnya, kegiatan ini diharapkan sebagai jembatan penghubung kerja sama antara bidang ilmu linguistik dengan ilmu neurologi terutama dalam menangani terapi bagi penderita disartria khususnya, dan penderita gangguan berbicara lainnya.

\section{Metodologi}

Secara umum penelitian ini dilakukan melalui beberapa langkah kerja, antara lain observasi dan pendekatan alami, percakapan terarah, penerapan MTL, pemahaman cerita dan gambar, simulasi perilaku verbal, dan evaluasi pada setiap kegiatan (Nunan, 1992). 
Langkah-langkah tersebut diwujudkan melalui metode dan teknik pengumpulan data, penganalisisan data, dan penyajian hasil analasis (Sudaryanto, 1993).

Populasi penelitian ini adalah tuturan verbal penderita disartria di RS M Djamil Padang. Sampel penelitiannya adalah tuturan verbal dari 4 orang penderita disartria yang peneliti amati selama 2 bulan, sedangkan 2 bulan berikutnya adalah pembuktian aplikasi terapi pada masa penyembuhan. Alasan dipilihnya 4 orang penderita disartria ini adalah karena dari beberapa orang penderita pasien penderita gangguan berbahasa dan berbicara yang ada di rumah sakit ini, 4 orang tersebut menunjukkan gejala gangguan berbicara kasus disartria. Keempat pasien ini 2 orang sedang menjalani rawat inap dan 2 orang lain menjalani rawat jalan. Skala keparahan gangguan komunikasi penderita berkisar antara 2-4 skala BDDE (Boston Diagnostic Disartria Examination). Seluruh pasien pendidikannya minimal SLTA dan telah tinggal di kota Padang lebih kurang sejak 10 tahun.

Dua dari 4 orang subjek penelitian ini awalnya menderita afasia broca dengan derajat keparahan skala 4 BDAE (Boston Diagnostic Aphasia Examination). Setelah 2 tahun mengalami stroke, orang itu menderita disartria skala 3. Satu orang mengalami disartria sejak awal karena adanya gangguan di saraf pusat yang mengontrol otot alat-alat ucapnya sejak 5 tahun terakhir, sedangkan yang satu orang lagi mengalami disartria sejak mengalami kecelakaan dan mengalami kelainan di organ alat ucapnya dengan skala 2 BDDE.

Tuturan penderita diperoleh dengan teknik yang standar, yakni penilaian terhadap tuturan pasien dengan cara: tanya jawab, penamaan objek, cerita gambar, dan penceritaan kembali. Topik yang ditanyakan adalah kegiatan sehari-hari, riwayat penyakit. Penamaan objek menggunakan tes standar Dharmaperwira (1996), sedangkan penceritaan gambar menggunakan perangkat Cookie Theft (Goodglass dan Kaplan 1982). Data ditranskripsikan dan dianalisis berdasarkan hasil rekaman.

\section{Hasil dan Pembahasan}

\subsection{Bentuk Lingual Tuturan Penderita Disartria}

Berdasarkan hasil penelitian, diperoleh 5 bentuk lingual kesilapan verbal penderita disartria, yaitu penggantian, penghilangan/pengguguran, penambahan, tidak berurutan, dan pemendekatan. Perbandingan persentasenya adalah 33:42:5:8:6. Banyaknya jumlah kesilapan penghilangan dan penggantian, menandakan bahwa penderita mengalami gangguan pada tahap pengkodean fonologi. Menurut Kohn (1993), apabila penderita mengalami gangguan dalam memproduksi fonem, ia cenderung menggugurkan bunyi guna mencapai aspek fonetik sebuah tuturan. Perbandingan kelima bentuk verbal tersebut dapat dilihat dari grafik berikut:

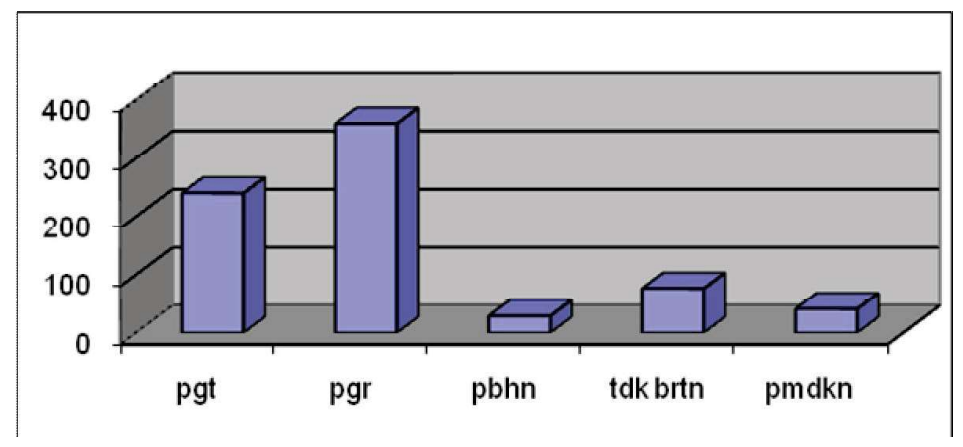

4 | Ranah, Volume 2, Nomor 2, Desember 2013 
Berdasarkan grafik di atas, terdapat bukti bahwa penderita disartria sering menghilangkan bunyi-bunyi dan memanfaatkan segmen awal sebagai strategi untuk mengakses usur leksikal yang dituju dengan meminimalkan penambahan bunyi. Mengganti bunyi hampir sering dilakukan akibat loncatan leksikal sehingga penderita mudah memutarbalikkan letak fonem dan suku kata. Pemendekan leksikal kadang dilakukan untuk tujuan kecepatan karena penderita cenderung bosan dalam melatih alat ucap apalagi terjadi pertanyaan yang berulang-ulang. Beberapa contoh di bawah ini menunjukkan bentuk-bentuk lingual dimaksud secara fonologis, data diperoleh sebelum dilakukan terapi terhadap subjek penelitian.

(!1) P : : Gambar seperti ini apa namanya pak?

SP2 : mba....ni...ni...kkkur.....ya...da...kurra...

ni....pi....sa....sap...

ini...ya....safi....

(23) $P \quad$ : Kalau iko apa artinya pak?

SP2 : ngan.....mRok...kok...., eh....bubu...kan, tapi korok di....setop....ya larang me....tokok.

(41) $P \quad$ : Bapak tinggal dima?

SP1 : tsawa an....kat...(berusaha mengangkat tangan)

( $\mathrm{P}=$ peneliti $\mathrm{S}=$ Subjek Penelitian)

Berdasarkan data tesebut, tampak bahwa penderita disartria mampu mencari unsur leksikal yang diperlukan. Karena saraf dan otot yang berfungsi untuk memproduksi urutan fonem dan leksikal yang dituju mengalami gangguan, leksikal yang dimaksud mengalami perubahan dan ketepatan bunyi. Apabila ini berlangsung dalam masa yang berketerusan untuk penempatan fonem yang tepat. Untuk itu penderita disartria memerlukan terapi yang berulang-ulang, sehingga saraf yang memerintahkan otot yang menggerakkan alatalat artikulasi dapat berfungsi dengan baik kembali.

Penderita disartria mengalami gangguan pada hemisfer kiri, atau lesi tertentu menyebabkan ia mengalami berbagai kesulitan leksiko-semantik. Penderita mengalami kesulitan dalam menemukan kata-kata, namun apabila kata-kata tersebut sering dipakai, maka dapat dikenali sebagai satu keseluruhan yang mempunyai arti semantik.

\subsection{Pengaruh Emosi terhadap Pengetahuan Leksikal dan Semantik}

Perasaan atau emosi juga berpengaruh terhadap pengetahuan leksikal dan semantik penderita, baik pengalaman perasaan primer (yang dibawa sejak lahir) maupun perasaan/ emosi sekunder. Seluruh gambar mental terikat dengan perasaan-perasaan tertentu, sedangkan emosi keseluruhan dapat memanggil respon-respon kimia yang mempengaruhi proses kognitif. Makna sebuah perasaan saling berhubungan dengan pengalaman. Oleh karena itu, melalui gambar-gambar maka emosi-emosi akan terus diadaptasikan oleh penderita dalam memaknai berbagai konsep leksikal. Dari sekian banyak jumlah data leksikal yang ditanyakan terhadap penderita, diperoleh perbandingan yang seimbang antara emosi dan pengetahuan, sedangkan leksikal semantik persentasenya cukup rendah. Hal ini menandakan bahwa emosi sangat berpengaruh terhadap leksikal pengetahuan meskipun pemaknaan terhadap kosakata masih kurang. Kekurangan tersebut dapat ditingkatkan 
melalui proses pelatihan terapi linguistik terhadapnya. Perbandingan ketiganya adalah 40 persen leksikal pengetahuan, 20 persen leksikal semantik, dan 40 persen leksikal perasaan.

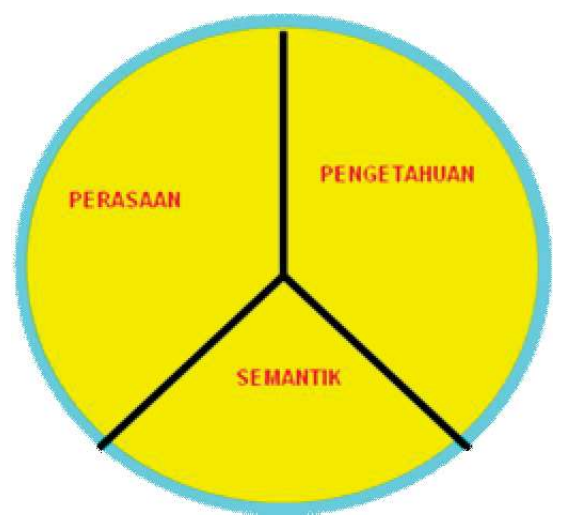

Beberapa contoh berikut memperlihatkan bahwa leksikal emosi mempengaruhi leksikal pengetahuan dan semantik tuturan verbal penderita disartria:

(19) $\mathrm{P} \quad$ : Bisa bapak ceritakan gambar ini?

SP3 : oo ni....anak ko ta...tabuguah...tafi....folici ko....datang sapak... haha....folici kini yapah.....diajek lu baru nyo totong.....aden yo cuko eee undak cuko jo folici do....ici utaknyo fiti ..jo...., aaa liek faja ko ha....kansang na bao honda......lah? (oo iko, anak ko tabunuah...tapi...polisi ko datang capek...ha... (polisi kini payah....disogok dulu baru nyo tolong.... aden iyo suko...eh....indak suko jo polisi do....isi utaknyo pitih sajo.... aa...lieklah paja ko....kancang bana baok honda......alah?) 'oh ini, anak ini terbunuh, tapi polisi ini datang cepat, eh...polisi sekarang susah.....dikasih uang dulu baru ia akan akan menolong, kalau saya tidak suka sama polisi, isi kepala nya uang saja. Lihatlah anak ini, kencang sekali bawa motor, Sudah?'.

Data tersebut menunjukkan bahwa penderita disartria punya leksikon pengetahuan tentang sebuah peristiwa kecelakaan. Walaupun peneliti bertanya dalam bahasa Indonesia, ia mamahami apa yang peneliti inginkan, yaitu menceritakan kembali sebuah gambar, yang isinya mengungkit emosi penderita bagaimana ia memaknai leksikal polisi berdasarkan pengalaman pengetahuannya. Dengan begitu penderita terbawa bagaimana memaknai konsep leksikal polisi sehingga gambar yang dimaksud tidak dapat diceritakan dengan sempurna. Ketika ditunjuk oleh PS ke arah gambar, penderita dapat menangkap kembali leksikal honda 'motor', tetapi tidak tepat dalam memaknai kata terbunuh dengan kata kecelakaan.

\subsection{Pencapaian Model Terapi Perilaku Penderita Disartria}

Berkomunikasi dengan penderita disartria ketika masa penyembuhan sebagai bentuk terapi, tidak saja lingual, tetapi dapat dilakukan secara auditif dan visual (penglihatan) dan taktil (perabaan). Penanganannya dapat melalui model terapi perilaku secara pemeriksaan. Urutan kerjanya adalah sebagai berikut. 
1. Informasi akan ditangkap melalui pendengaran, penglihatan, serta perabaan dan sampai di otak posterior.

2. Pada tingkat kortikal terjadi pengolahan secara sadar. Pengintegrasian terus terjadi melalui berbagai stimulus. Pengetahuan semantik dan arti emosional dalam hal ini terjadi.

3 Pada tingkat kortikal, pengolahan daya ingat terus terintegrasi dari berbagai stimulus pancaindra. Kemudian penderita akan membandingkan dengan pengetahuan semantik.

4 Sebuah tindakan akan dipertimbangkan di daerah pre-frontal dan dilakukan berbagai pilihan. Akhirnya sebuah pikiran menjadi impuls dalam menjalankan proses selektif dari berbagai leksikal yang tersimpan di otak.

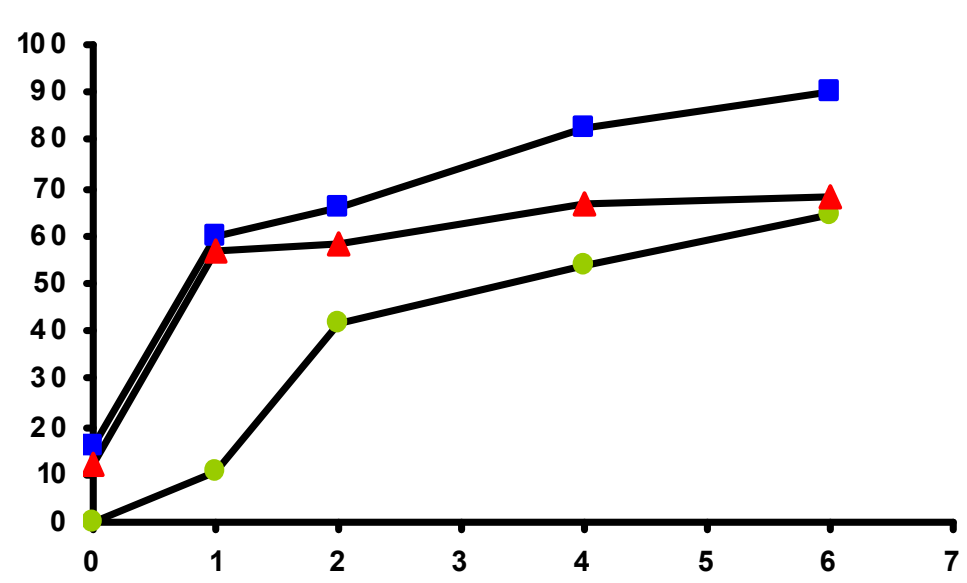

Oleh karena itu, terapi perilaku (terkait dengan perasaan/emosi) sangat diperlukan dalam menanganigangguan berbahasa penderita disartria, terutama masa penyembuhannya karena diperkirakan fungsi hemisfer kanannya tidak mengalami gangguan.

Setelah dilakukan penerapan terapi linguistik dengan metode terapi perilaku terhadap penderita disartria selama 2 bulan, secara berturut-turut 2 jam dalam setiap 2 hari, maka diperoleh peningkatan ketepatan fonologis dan leksikal. Pada bulan terakhir diperoleh ketepatan makna yang dimaksud sesuai dengan apa yang diharapkan oleh sebuah peristiwa tutur. Pencapaian ini sebagai bukti terdapat peningkatan kemampuan berkomunikasi penderita. Dari kurang lebih 50 peristiwa tutur yang digunakan, hampir 90 persen terdapat grafik kenaikan dalam hal ketepatan pelafalan dan ketepatan kata. Grafik indeks capaian yang diperoleh berdasarkan penghitungan kesilapan fonologi, leksikal, dan semantik tampak seperti berikut:

Mulai dari informasi yang diperoleh penderita disartria, sampai kepada tingkat kortikal dan tindakan yang dipilih menjadi impuls selektif di otak, terjadi peningkatan. Peningkatan secara drastis terjadi pada minggu pertama dan kedua, dikarenakan adanya kejutan pancaindra dan kedekatan emosional yang diberikan terhadap penderita disartria. Kemudian mulai dari minggu kedua sampai minggu keenam terdapat kestabilan pengucapan yang tidak menurun, baik pengayaan pengetahuan, leksikal, maupun pemahaman terhadap peristiwa tutur yang diulang-ulang. Pengulangan dilakukan agar terjadi penyimpanan fonem dan leksikal yang stabil antara pengetahuan dan pemaknaan. 


\section{Simpulan}

Dari penelitian singkat yang telah dilakukan terhadap penderita disatria, dapat disimpulkan bahwa gangguan berbicara pada penderita disartria merupakan gangguan koordinasi saraf yang menggerakkan otot-otot fungsi bicara seseorang. Gangguan tersebut memiliki skala keparahan akibat gangguan fungsi kerja saraf bahasa di otak. Seseorang mengalami disartria bisa saja disebabkan oleh karena terjadinya gangguan berbahasa (language disorder), misalnya akibat stroke yang dialami seseorang maka gejala yang tampak awal adalah disartria. Akan tetapi, penderita disartria bukanlah seluruhnya terjadi karena adanya stroke, boleh jadi gangguan berbicara yang dialaminya. Ketidaknormalan alat-alat bicara itu terjadi gangguan artikulasi, atau faktor eksternal yang menyebabkan ketidaktepatan dalam menggunakan organ bicara sehingga terjadi gangguan linguistik terutama aspek fonologi dan leksikal.

Berbagai gejala linguistik yang tampak dari perilaku verbal penderita disartria, yang paling tinggi persentase kesilapannya adalah verbal penghilangan, sedangkan pengaruh emosi terhadap kebertahanan leksikal pengetahuan dan leksikal perasaan terdapat keseimbangan penampakan, dan pemahaman terhadap makna leksikal yang diharapkan sedikit rendah dibanding leksikal pengetahuan dan leksikal perasaan. Untuk meningkatkan kemampuan berkomunikasi penderita disartria, dapat dilakukan upaya terapi linguistik dengan menerapkan motode terapi perilaku. Penerapannya menunjukkan indeks lingual yang meningkat sehingga perilaku verbal setelah menjalani terapi jauh lebih baik dibandingkan dengan sebelum menjalani terapi. Melalui berbagai stilmulus dari metode yang diterapkan membuktikan bahwa telah terjadi peningkatan ketepatan kemampuan lingual penderita disartria dari aspek fonologi, leksikal, dan semantik. 


\section{Daftar Pustaka}

Adams and Victor's. 2002. Manual of Neurology. New York: McGraw-Hill Companies. Adams and Victor's. 2009. Principles of Neurology. New York: McGraw-Hill Companies.

Blumstein, S. 1994. Language: Psychological dan Biological. Cambridge

Univ. Dharmaperwira dan Prins. 2004. Gangguan-gangguan Komunikasi. Jakarta: Djambatan.

Chaer, Abdul. 2003. Psikolinguistik: Kajian Teoritik. Jakarta: Rineka Cipta.

------ 2007. Linguistik Umum. Jakarta: Rineka Cipta.

Corwin, Elizabeth. 1997. Patofiologi. Jakarta: EGC.

Dardjowidjojo, S. 2003. Psikolinguistik Pengantar Pemahaman Bahasa Manusia. Jakarta: Yayasan Obor Indonesia.

Dharmaperwira, Reni I.I dan Prins. 2000. Disartria-Apraksia Verbal dan TEDYVA. Jakarta: Indomedika.

Evans, R.W. 1999. Diagnostic Testing in Neurology. Philadelphia: Saunders Company.

Goldrick, Matthew.2010.Linking Speech Errors and Generative PhonologicalTheory. Northwestern University.

Ingram,J.C.L. 2007. Neurolinguistics:An IntroductiontoSpoken LanguageProcessing and Its Disorder. New York: Cambridge University Press.

Keraf, Gorys. 1984. Komposisi. Jakarta: Nusa Indah.

Listiani, Endang. 2009. "Penyimpangan Fonologis pada NS (Studi Kasus Pasien Disartria di Rumah Sakit Jiwa Pusat Surakarta." Skripsi. Solo: Universitas Sebelas Maret.

Moleong, Lexy J. 2005. Metode Penelitian Kualitatif. Bandung: Remaja Rosdakarya.

Rachmawati, Endah. 2003. Proses Pengubahan Perilaku dalam Terapi Wicara pada Penderita Disartria. Skripsi. Malang: Universitas Muhammadiyah Malang.

Sastra, Gusdi. 2005. Ekspresi Verbal Penderita Strok dari Sudut Analisis Neurolinguistik. Disertasi. Kuala Lumpur: Universiti Putra Malaysia.

Sastra, Gusdi. 2007. "Metode Terapi Perilaku bagi Penderita Stroke." Prosiding Conaplin. Bandung: Universitas Pendidikan Indonesia.

Sastra, Gusdi. 2010. Neurologi Bahasa. Padang: Andalas University Press.

Sudaryanto. 1992. Metode Linguistik. Yogyakarta: Gadjah Mada University Press.

------- 1993. Metode dan Aneka Teknik Analisis Bahasa: Pengantar Penelitian Wahana Kebudayaan Secara Linguistis. Yogyakarta: Duta Wacana University Press.

Travis, L.E. 1971. Handbook of Speech Patology and Audiology. New York:Appleton Century.

Sukmayanti. 2006. "Kemampuan Bahasa Lisan Penderita Disartria: Suatu Tinjauan Psikolinguistik." Skripsi. Padang: Universitas Andalas.

Vijayaletchumy $a / p$ Subramaniam. 2008. "Disleksia dalam Konteks PembelajaranBahasa di Malaysia." Pertanika Journal of Social Sciences and Humanities. 16(2): 115-139. 